\title{
Cropping Pattern and Socio-Economic Study of Ethnic People in the Hilly Areas of Bangladesh
}

\author{
Joti Lal Barua ${ }^{1 *}$, Nazrul Islam Khan ${ }^{2}$, Sagarmay Barua ${ }^{2}$, Sayed Mohammad Mohsin ${ }^{3}$ \\ and M. R. Islam ${ }^{4}$ \\ ${ }^{I}$ BIRTAN; ${ }^{2}$ INFS, Dhaka University; ${ }^{3}$ Department of Plant Pathology, Sher-e-Bangla Agricultural \\ University, Dhaka-1207; ${ }^{4}$ Soil Resources Development Institute (SRDI), Bangladesh \\ *Corresponding author and Email: baruajoti@gmail.com
}

Received: 12 December 2014 Accepted: 06 June 2015

\begin{abstract}
The study was conducted at some hilly areas of Bangladesh during the period of January to May 2009 and during April to May, 2010. This was done to evaluate socio-economic condition of the ethnic people and to find out the existing cropping pattern in the hilly areas of Bangladesh. A total of 810 households from Rangamati, Khagrachari and Bandarban were selected randomly. Socio-economic profiles of the households indicated that the most household respondent belonged to thirty-forty five years age group followed by forty five- sixty years, fifteen- thirty years and sixty-seventy five years age group. This indicates that household respondents were younger (thirty-forty five years) in the study areas. It was found that, among the tribal people Marma were found highest rate of illiteracy followed by Shaontal, Tanchanga, Chakma, and Tripura. The tribal people of Tripura were not found to be below Primary level in the study area. The percentage of agriculture and service were found equal in Chakma tribal people in the study area. The Marma people were not found as a service holder because of their low education level. Cultivable land use pattern among the ethnic people revealed that out of 810 ethnic households 222 households were involved in cultivation (27.4\%). It also showed that $55.4 \%$ households harvested single crop, 26.3\% households harvested double crops, $10.8 \%$ households harvested triple crops in a year and only $7.5 \%$ households practiced jhum cultivation.
\end{abstract}

Keywords: Cropping pattern, ethnic people, Bangladesh

\section{Introduction}

Agriculture is the science and practice of producing crops and cropping pattern expresses the shares of various crops in the farmers' total cultivated area in an agricultural year. Cropping pattern is an important indicator of a farmer's decision making ability and also influences the consumption pattern as well as health and nutritional status of the people. Cropping pattern vary from region to region, country to country and culture to culture. Cropping systems of a region are decided by and large, by a number of soil and climatic parameters which determine overall agro-ecological setting for nourishment and appropriateness of a crop or set of crops for cultivation. The Chittagong Hill Tracts (CHT) of Bangladesh presents unique biophysical characteristics, ethnic diversity and farming practices. The ethnic people of this hilly area of Bangladesh are also following certain pattern of cropping culture in their respective areas. The lives of the indigenous people are centred on the hills and their resources. The wide variety of 
plants and animals in the hills has taken care of the lives support system of the hill people including dwelling, food, clothing, health care, festivities and other activities (Khisa, 1998). Indigenous people in Bangladesh are, in general, very poor, illiterate, and their livelihood depends on wage earnings and shifting cultivation (Uddin et al., 2000). They receive the highest income from agriculture compared to other sources, but are constrained by limited cash and modern technology for higher agricultural production , which is a threat to the natural resources in the area (Farid and Mujibullah, 1990; Chowdhury et al., 2004). Livestock and poultry provide additional income. Most households own a single small dwelling with no modern amenities and their main source of drinking water is natural springs (Miah and Islam, 2007).

The economy of the region is predominantly agricultural. Because of the nature of the terrain the indigenous people of the CHT developed the system of cultivation called jhum which is also known as "'shifting", "rotational", "slash and burn" agriculture. Population growth, settler influx and the loss of land have contributed over time to the decline of production; as a consequence the communities experience moderate to severe food shortages on a seasonal basis fact that reflects the dependence on agricultural cycles. Households have sufficient quantities of food from their own production for less than half year (MSF-Holland, 2008). The Chakma people living in Bangladesh used to meet their daily needs mostly from natural forest products. For the primary health care, still most of them depend upon surrounding plants and plant products (Roy et al., 2008).

The existing cropping pattern in the hilly areas of Bangladesh to be changed for the adoption of better pattern in order to increase production to meet the various required crops and also to give more economic return to the household (Farmer) which leads to increased income. Increased income means increased purchasing capacity, which leads to adequate consumption of required food. Thus, the agricultural cropping pattern affects on food consumption. Proper nutrition is the fundamental basic requirement for positive health, functional efficiency and productivity. As the production and supply of food items is directly related to agriculture, therefore agricultural cropping pattern is an integral constituent of food security. Increased attention to nutrition can enable the agricultural sector to better meet of its own needs.

The government of Bangladesh has taken special attention for the overall development of tribal. Based on the above situations, the present study has given much emphasis on focusing the issue of individual household food security, especially in the proper segment of the population like indigenous people who are actually subsistence farmers and forest dwellers, and vulnerable to various natural calamities. The present study was undertaken to find out the socio-demographic condition and agricultural cropping pattern of the ethnic people of the Chittagong Hill Tracts of Bangladesh.

\section{Materials and Methods}

To study the agricultural cropping patterns and to investigate the present socio-economic condition of the ethnic people, a multistage cluster sampling was designed for selecting the farm households from the uplands of the Hill Tracts of Chittagong. The sampling framework were consist of primary sampling unit of district, secondary sampling unit of upazila, pre-ultimate sampling unit of village and ultimate sampling unit of household for the data collection. Selection of area was quite difficult as there were three districts in the CHT consisting of 25 subdistricts (Upazila) in total. Out of these 25, there were 10 Upazila in Rangamati, 8 in Khagracahari, and 7 in Bandarban District. Considering the available time, budget, accessibility of interviewees and all other aspects two Upazila from each district and five villages from each Upazila were randomly selected. A total of 810 households those who were engaged in agriculture were randomly selected from these three districts. The study was a descriptive cross- 
sectional which were followed a mixed method approach, combining both quantitative and qualitative analysis. The exercise of mixed methods involves the collection, analysis and mixing of both quantitative and qualitative data in a single study (Barkat, 2009). Several methodological tools were thus used including observation, individual interviews and group discussions.

Data were collected from the selected households through face-to-face interview with each of the head of the families of 810 households during January to May 2009 and during April to May, 2010. To get the information, the household head (male) and the spouse were interviewed. Every day, the collected information/data was checked, coded and cross checked by the interviewers and finally by the supervisor at the field sites in order to avoid any misreporting. Any confusion arising out of this matter was settled on the following day during subsequent home visits. The questionnaire was edited and data mean entered into SPSS program. Data entry was done by the computer data entry personnel of INFS, DU and this was followed by an extensive period of logical checking to identify any error in data entry, which were then corrected by consulting the original questionnaires.

\section{Results and Discussion}

In order to get a complete picture of socioeconomic condition of the ethnic people in the hilly areas, some important characteristics such as age, occupation, level of education, family monthly income and expenditure and existing cropping pattern had been considered in this study. In the study areas, cultivable land use pattern among the ethnic people (Table 1) revealed that out of 810 ethnic households 222 households were involved in cultivation $(27.4 \%)$. It also showed that $55.4 \%$ households harvested single crop, $26.3 \%$ households harvested double crops, $10.8 \%$ households harvested triple crops in a year and $7.5 \%$ households practiced jhum cultivation.

Socioeconomic characteristics of the tribal people were found to be important in decision making about cropping pattern, production plan and day-to-day household activities. They differ from each other in respects of education level, occupation, age distribution, monthly income and expenditure of the ethnic household. Socioeconomic characteristics were influenced them to select cropping pattern for their agriculture livelihood.

\subsection{Education of the households heads}

The sample households were classified into seven categories based on their education level. It was found that $34.3 \%$ Chakma, $78.9 \%$ Marma, $56.8 \%$ Shaontal, 27\% Tripura, and $46.7 \%$ Tanchanga had no education (Table 2). The data showed that among the tribal population below primary education maximum $(8.3 \%)$ was found in Chakma and Tripura were not found in the study area.

Table 1. Cultivable land use pattern among the Ethnic people $(\mathrm{N}=222$ households)

\begin{tabular}{lcc}
\hline No. of crop harvested in a year & No. of households & Percent of households \\
\hline Single cropped & 123 & 55.4 \\
Double cropped & 58 & 26.3 \\
Triple cropped & 24 & 10.8 \\
Jhum cultivation & 17 & 7.5 \\
\hline Total & 222 & 100 \\
\hline
\end{tabular}

Note: Among the total households $27.4 \%$ households involve in cultivation. 
The data revealed that below SSC maximum (26.7\%) was found in Tanchanga and Marma were not found in the study area. It also found that below HSC maximum $(37.8 \%)$ in Tripura and HSC and above maximum $(21.3 \%)$ in Chakma. It was found that, among the tribal people Marma were found highest rate of illiteracy followed by Shaontal, Tanchanga, Chakma, and Tripura.

\subsection{Occupation of the households heads}

The data were revealed that about two thirds of Chakma people were engaged in agriculture (33.3\%) and service $(33.3 \%)$ and remaining one third were spread over to the occupation of earth cutting $(0.9 \%)$, rickshaw/van driver $(2.8 \%)$, business (4.6\%) and unnamed occupation (25\%) (Table 3). Marma people as they have no good education they were engaged in agriculture (39.4\%) and uncertain jobs (43.7\%). No service men were found among them. Shaontal people were mainly engaged in agriculture (43.2\%) and uncertain jobs (33\%). Overwhelming majority of Tripura people were involved in service $(81.1 \%)$. More than half $(53.3 \%)$ of the respondents of Tanchanga had occupation of uncertain jobs followed by agriculture $(27.7 \%)$ and business (13.3\%). So, majority of the respondents of tribal people had either agriculture or uncertain jobs except Tripura.

\subsection{Age distribution of the households heads}

Age is an important factor that influences household production decision and efficiency and to adopt improve technologies. The percentage distribution of sample respondents according to age group was given in Table 4. Most household respondent belong to thirty-forty five years age group followed by forty five- sixty years, fifteen- thirty years and sixty-seventy five years age group. This indicates that household respondent were younger (thirty-forty five years) in the study areas.

\subsection{Family monthly income and expenditure}

The household income, expenditure and savings of the sample households play an important role in attaining household level food security level in study areas. The incomes of respondent household come from different sources; these were farm income, livestock income, non-farm income and income from selling bamboo, fire wood, timber and sweeping materials. Farm income includes income from crops, vegetable and fruit produced in household homestead areas, plain land area, hilly area, under their occupation. Livestock income comprises of income from sale of cow, goat, pig, chicken, and milk. The non-farm income comes from labor wages, service and petty business. The household were categorized into five groups based on their monthly income (Table 5). The data were revealed that the monthly income of the most tribal peoples of Chakma, Marma, Shaontal, Tripura and Tanchanga were found below Taka 5000 followed by taka 5001-8000. The most tribal peoples of Tanchanga and others were found taka 5001-8000 monthly income group. The monthly household expenditure for food and non-food items and the expenditure were crop production, food, clothes, medication, housing, children's education, social/religious functions, livestock rearing, chicken rearing, and expenditures from biri, cigarettes, tobacco, betel leaf, and tea. The data revealed that family monthly expenditure were higher among the tribal people of Tripura followed by Chakma, Tanchanga, Marma and Shaontal.

The evolving land use pattern in the hilly region of Bangladesh clearly reflects three different stages of agricultural development. The extensive land-use type still remains at a basic stage of agricultural development, just one step ahead of gathering and hunting (Ofori, 1973; Okigbo, 1984). Shifting cultivation was the only form of agriculture in CHT (Lewin, 1869). With poor productive resources, the farmers were facing serious difficulties to meet their subsistence requirements. Yields were declining because of decreasing soil fertility caused by shortened fallow period under the influence of growing population pressure and reduced available land for shifting cultivation. 
Table 2. Education level of household head in the study area

\begin{tabular}{|c|c|c|c|c|c|c|c|c|c|c|c|c|}
\hline \multirow{2}{*}{ Level of education } & \multicolumn{2}{|c|}{ Chakma } & \multicolumn{2}{|c|}{ Marma } & \multicolumn{2}{|c|}{ Shaontal } & \multicolumn{2}{|c|}{ Tripura } & \multicolumn{2}{|c|}{ Tanchanga } & \multicolumn{2}{|c|}{ Others } \\
\hline & Frequency & $\%$ & Frequency & $\%$ & Frequency & $\%$ & Frequency & $\%$ & Frequency & $\%$ & Frequency & $\%$ \\
\hline Below primary & 20 & 8.3 & 9 & 5.6 & 2 & 2.3 & - & - & 2 & 3.3 & 14 & 8.1 \\
\hline Below SSC & 48 & 20.4 & - & - & 27 & 10.2 & 19 & 21.6 & 19 & 26.7 & 34 & 20.3 \\
\hline Below HSC & 26 & 11.1 & 18 & 11.3 & 4 & 4.5 & 33 & 37.8 & 5 & 6.7 & 15 & 9.3 \\
\hline HSC and above & 51 & 21.3 & - & - & 1 & 1.1 & 9 & 10.8 & - & - & 11 & 6.4 \\
\hline Illiterate & 82 & 34.3 & 127 & 78.9 & 50 & 56.8 & 24 & 27.0 & 33 & 46.7 & 70 & 41.9 \\
\hline Can sign only & 9 & 3.7 & 7 & 4.2 & 4 & 4.5 & 2 & 2.7 & 12 & 16.7 & 23 & 14.0 \\
\hline Can read and sign & 2 & 0.9 & - & - & - & - & - & - & - & - & - & - \\
\hline Total & 238 & 100 & 161 & 100 & 88 & 100 & 87 & 100 & 70 & 100 & 166 & 100 \\
\hline
\end{tabular}

Table 3. Occupation of household head in the study area

\begin{tabular}{|c|c|c|c|c|c|c|c|c|c|c|c|c|}
\hline \multirow{2}{*}{ Occupation } & \multicolumn{2}{|c|}{ Chakma } & \multicolumn{2}{|c|}{ Marma } & \multicolumn{2}{|c|}{ Shaontal } & \multicolumn{2}{|c|}{ Tripura } & \multicolumn{2}{|c|}{ Tanchanga } & \multicolumn{2}{|c|}{ Others } \\
\hline & Frequency & $\%$ & Frequency & $\%$ & Frequency & $\%$ & Frequency & $\%$ & Frequency & $\%$ & Frequency & $\%$ \\
\hline Agril. (work) (1) & 79 & 33.3 & 63 & 39.4 & 38 & 43.2 & - & - & 19 & 26.7 & 46 & 27.9 \\
\hline Earth cutting (2) & 2 & 0.9 & - & - & - & - & - & - & - & - & - & - \\
\hline Rickshaw/van driver (5) & 7 & 2.8 & 7 & 3.2 & 4 & 4.5 & - & - & 2 & 3.3 & 4 & 2.3 \\
\hline Business (7) & 11 & 4.6 & 11 & 7.0 & - & - & 7 & 8.1 & 9 & 13.3 & 8 & 4.7 \\
\hline Jobless (9) & - & - & 9 & 5.6 & 5 & 5.7 & - & - & - & - & 2 & 1.2 \\
\hline Service (11) & 79 & 33.3 & - & - & 12 & 13.6 & 71 & 81.1 & 2 & 3.3 & 20 & 12.2 \\
\hline Others (12) & 60 & 25.0 & 70 & 43.7 & 29 & 33.0 & 9 & 10.8 & 37 & 53.3 & 86 & 51.7 \\
\hline Total & 238 & 100 & 161 & 100 & 88 & 100 & 87 & 100 & 70 & 100 & 166 & 100 \\
\hline
\end{tabular}


Table 4. Age (year) distribution in the study area

\begin{tabular}{|c|c|c|c|c|c|c|c|c|c|c|c|c|}
\hline \multirow{2}{*}{ Age categories } & \multicolumn{2}{|c|}{ Chakma } & \multicolumn{2}{|c|}{ Marma } & \multicolumn{2}{|c|}{ Shaontal } & \multicolumn{2}{|c|}{ Tripura } & \multicolumn{2}{|c|}{ Tanchanga } & \multicolumn{2}{|c|}{ Others } \\
\hline & $\mathrm{N}$ & Mean \pm sd & $\mathrm{N}$ & Mean \pm sd & $\mathrm{N}$ & Mean \pm sd & $\mathrm{N}$ & Mean \pm sd & $\mathrm{N}$ & Mean \pm sd & $\mathrm{N}$ & Mean \pm sd \\
\hline $15-30$ & 31 & $26.5 \pm 3.01$ & 20 & $28.1 \pm 2.52$ & 14 & $27.6 \pm 2.41$ & 12 & $27.4 \pm 4.22$ & 14 & $28.2 \pm 1.94$ & 18 & $27.8 \pm 2.07$ \\
\hline $30-45$ & 145 & $38.3 \pm 3.82$ & 63 & $38.5 \pm 3.96$ & 42 & $37.2 \pm 4.27$ & 49 & $39.7 \pm 3.88$ & 33 & $38.4 \pm 4.07$ & 78 & $38.1 \pm 4.30$ \\
\hline $45-60$ & 53 & $53.1 \pm 4.57$ & 57 & $53.5 \pm 4.27$ & 28 & $52.8 \pm 3.50$ & 16 & $51.6 \pm 3.69$ & 19 & $52.8 \pm 4.98$ & 58 & $52.8 \pm 4.25$ \\
\hline $60-75$ & 9 & $69.5 \pm 4.20$ & 20 & $66.4 \pm 3.09$ & 4 & $66.0 \pm 4.24$ & 9 & $66.3 \pm 2.99$ & 5 & $70.0 \pm 1.09$ & 13 & $66.5 \pm 4.29$ \\
\hline Total & 238 & $41.2 \pm 10.50$ & 161 & $46.2 \pm 12.4$ & 88 & $42.0 \pm 11.1$ & 87 & $43.1 \pm 11.3$ & 70 & $42.3 \pm 12.1$ & 166 & $44.3 \pm 11.3$ \\
\hline
\end{tabular}

Table 5. Family monthly income and expenditure (taka) in the study area

\begin{tabular}{|c|c|c|c|c|c|c|c|c|c|c|c|c|}
\hline \multirow{2}{*}{$\begin{array}{l}\text { Monthly income } \\
\text { (TK) }\end{array}$} & \multicolumn{3}{|c|}{ Chakma } & \multirow{2}{*}{$\frac{\text { Marma }}{\text { Mean } \pm \text { sd }}$} & \multicolumn{3}{|c|}{ Shaontal } & \multicolumn{2}{|l|}{ Tripura } & \multicolumn{2}{|l|}{ Tanchanga } & \multirow{2}{*}{$\begin{array}{c}\text { Others } \\
\text { Mean } \pm \text { sd }\end{array}$} \\
\hline & $\mathrm{N}$ & Mean \pm sd & $\mathrm{N}$ & & $\mathrm{N}$ & Mean \pm sd & $\mathrm{N}$ & Mean \pm sd & $\mathrm{N}$ & Mean \pm sd & $\mathrm{N}$ & \\
\hline$<5000$ & 145 & $3090 \pm 949$ & 138 & $2780 \pm 1088$ & 82 & $2343 \pm 1268$ & 24 & $3640 \pm 1418$ & - & - & - & - \\
\hline $5001-8000$ & 57 & $6965 \pm 884$ & 20 & $6444 \pm 846$ & 5 & $6100 \pm 548$ & 19 & $6875 \pm 991$ & 56 & $2739 \pm 1066$ & 130 & $3055 \pm 1182$ \\
\hline $8000-11000$ & 18 & $9375 \pm 694$ & - & - & 1 & 10000.0 & 24 & $9500 \pm 667$ & 7 & $7000 \pm 1000$ & 25 & $6301 \pm 832$ \\
\hline $11000-14000$ & 11 & $12600 \pm 894$ & - & - & - & - & 9 & $12375 \pm 478$ & 5 & $9500 \pm 707$ & 9 & $9709 \pm 923$ \\
\hline$>14000$ & 7 & $16670 \pm 2887$ & - & - & - & - & 12 & $23200 \pm 11344$ & 2 & $14000 \pm 210$ & 2 & $12000 \pm 304$ \\
\hline Total & 238 & $5306 \pm 3462$ & 161 & $3265 \pm 1635$ & 88 & $2643 \pm 1704$ & 87 & $9510 \pm 7292$ & 70 & $4034 \pm 2997$ & 166 & $4004 \pm 2286$ \\
\hline $\begin{array}{l}\text { Monthly } \\
\text { expenditure (TK) }\end{array}$ & 238 & $6574 \pm 4392$ & 161 & $3768 \pm 1754$ & 88 & $3125 \pm 998$ & 87 & $10512 \pm 1189$ & 70 & $5345 \pm 1979$ & 166 & $5478 \pm 2137$ \\
\hline
\end{tabular}


These conditions facilitated the transition from a cereal based extensive type of land-use system to a perennial crop-based intensive system. Similar experiences were reported from northern Thailand (Rerkasem and Rerkasem, 1994; Turkelboom et al., 1996) and from Sub-Saharan Africa (Pingali et al., 1987) and the Alpine region of Europe (Allan, 1986). Shifting cultivators in the lower-lying areas adjacent to the plain region, were also confronted with increasing land-resource scarcity arising from population growth. Wherever it was feasible, the people in these areas adopted a system of annual cropping integrated with livestock raising and agro-forestry.

Barkat et al. (2009) reported the CHT population is comparatively young age-structured which corresponds to the age structure of the national population. About $58 \%$ of the population belongs to below 24 years, and 5\% belong to 60 years and above. About $7.8 \%$ of all CHT people (age of 5 years and above) completed primary education and $2.4 \%$ completed secondary education. The average year of education is 2.8 . Barkat et al. (2009) also reported a notable proportion of CHT population is unemployed (23.5\%). Slight less than one-fourth of the population is child/disabled/old age (23.4\%). The cumulative percentage of indigenous households has reported income from the agriculture related source is about $136 \%$. The average annual net income of a rural household in the region irrespective of ethnicities is about Tk. 65,852 . Over $50 \%$ of the annual net income of all CHT households comes from sources related with agriculture; non-farm wages constitute about $15 \%$ closely followed by business related sources $(13 \%)$. The household annual expenditure in rural CHT is lower than that of rural Bangladesh (TK. 62,283 vs. 73,000). Confronted with all these difficulties, the people in these remote sloping lands continue to practice their traditional shifting cultivation, but in shorter cycles with a reduced fallow periods.

\section{Conclusions}

The present study provides a brief representation on agricultural cropping pattern among the ethnic people of Chittagong Hill Tracts. It also provides an insight into their life style, food security, health and nutrition. Education has not yet reached every household member in the hilly area. Main occupation of different tribal people such as Chakma, Marma, Shaontal, Tanchanga was found to be agriculture. Life style, food security, health and nutritional status of the ethnic people are greatly influenced by their agricultural cropping pattern. So, further efforts should be continued for the promotion and sustainable crop production in the hilly areas of Bangladesh. The hill farmers have limited knowledge about post harvest processing of fruits and vegetables. For his reason, a number of products get lost before marketing. So, postharvest technology program for horticultural crops should be introduced in the hilly areas. The government should take necessary initiatives to set up agro- processing industries in Rangamati Sador which is the middle place of CHT. Jhum farming cannot be suddenly discontinued. In this situation, jhum cultivation should be modernized through replacing jhum crops with modern crop varieties suitable for hill farming.

\section{References}

Allan, N. J. R. 1986. Accessibility and altitudinal zonation models of mountains. Mt. Res. Dev. 6: 11-18.

Barkat, A., Halim, S., Poddar, A., Badiuzzaman, M., Osman, A., Khan, M. S., Rahman, M., Majid, M., Mahiyuddin, G., Chakma, S., Bashir, S. 2009. Socio-Economic Baseline Survey of Chittagong Hill Tracts, conducted for UNDP-CHTDF, by Human Development Research Centre (HDRC), Dhaka. 
Chowdhury, M. M. U., Rabbani, M. G., Zubair, S. M. and Islam, M. S. 2004. Study on the socioeconomic condition of hill farmers and their consciousness regarding soil degradation and conservation practices. $J$. Soil Health \& Environment, 1(2): 105112.

Farid, A. T. M. and Mujibulla, M. 1990. A socio-economic appraisal of farmers of the Chittagong Hill Tracts. Bangladesh. $J$. Agril. Res., 15: 52-58.

Khisa, 1998. Ethnobotanical and cultural background of ethnic communities of forest resource management in Chittagong Hill Tracts. In Banik R. L., Alam, K., S. J. Pel, \& Rastogi, A. (ed.), Applied Ethnobotany. Proceedings of Sub regional Training Workshop on Applied Ethnobotany, BFRI, Chittagong, Bangladesh. 56-63 pp.

Lewin, T. H. 1869. The Hill tracts of Chittagong and the dwellers therein, with comparative vocabularies of the hill dialects. Calcutta, India: Bengal Printing Company Ltd.

Miah, M. A. M. and Islam, S. M. F. 2007. Shifting Cultivation and Its Alternatives in Bangladesh: productivity, risk and Discount Rates. SANDEE working paper no. 24, September 2007. (Available at : www. Sandeeonline. org).

MSF-Holland. 2008. Food security Assessment report Chittagong hill tracts Sajek union April 2008.

Ofori, C. S. 1973. Shifting cultivation: reasons underlying its practice. FAO Soils Bulletin, FAO, Rome, Italy. 24: 14-36.
Okigbo, B. N. 1973. Improved permanent production systems as an alternative to shifting cultivation. FAO Soils Bulletin, FAO, Rome, Italy. 53: 1-100.

Pingali, P., Bigot, T., and Binswanger, P. H. 1987. Agricultural mechanization and the evolution of farming systems in SubSaharan Africa Baltimore, MD, USA: The Johns Hopkins University Press (A World Bank publication). $216 \mathrm{p}$.

Rerkasem, K., and Rerkasem, B. 1994. Shifting cultivation in Thailand: its current situation and dynamics in the context ofhighland development. IIED forestry and land use series, 3 Endsleigh Street, London, UK: IIED. 4: 108.

Roy, S., Uddin, M, Z., Hassan, M. A. and Rahman, M. M. 2008. Medico-botanical report on the Chakma community of Bangladesh. Bangladesh J. Plant Taxon., 15(1): 67-72.

Turkelboom, F., Van, K. K., Ongprasert, S., Sutigoolabud, P., and Pelletier, J. 1996. The changing landscape ofthe Northern Thai hills: adaptive strategies to increasing land pressure. Montane Mainland Southeast Asia in transition. Thailand: Chiang Mai University. 436$461 \mathrm{pp}$.

Uddin, M. S. 2000. Hill Farming System and Resource Utilization in the Chittagong Hill Tracts: A base line survey, Hill Research Station, Khagrachari, BARI, Joydebpur, Gazipur. 